\title{
Zymographic assay of plant diamine oxidase on entrapped peroxidase polyacrylamide gel electrophoresis. A study of stability to proteolysis
}

\author{
Carmen Calinescu • Rodolfo Federico • \\ Bruno Mondovi • Mircea Alexandru Mateescu
}

Received: 4 August 2009/Revised: 6 November 2009 / Accepted: 8 November 2009/Published online: 29 November 2009

(C) The Author(s) 2009. This article is published with open access at Springerlink.com

\begin{abstract}
A zymographic assay of diamine oxidase (DAO, histaminase, EC 1.4.3.6), based on a coupled peroxidase reaction, and its behavior at proteolysis in simulated gastric and intestinal conditions, are described. The DAO activity from a vegetal extract of Lathyrus sativus seedlings was directly determined on sodium dodecyl sulfate polyacrylamide electrophoretic gels containing entrapped horseradish peroxidase, with putrescine as substrate of histaminase and ortho-phenylenediamine as co-substrate of peroxidase. The accumulation of azo-aniline, as peroxidase-catalyzed oxidation product, led to well-defined yellow-brown bands on gels, with intensities corresponding to the enzymatic activity of DAO. After image analysis of gels, a linear dependency of DAO content (Coomassie-stained protein bands) and of its enzymatic activity (zymographic bands) with the concentration of the vegetal extract was obtained. In simulated gastric conditions $\left(\mathrm{pH} 1.2,37^{\circ} \mathrm{C}\right)$, the DAO from the vegetal extract lost its enzymatic activity before $15 \mathrm{~min}$ of incubation, either in the presence or absence of pepsin. The protein pattern (Coomassie-stained) revealed that the DAO content from the vegetal extract was kept
\end{abstract}

C. Calinescu $\cdot$ M. A. Mateescu $(\triangle)$

Department of Chemistry and Centre BioMed,

Université du Québec à Montréal,

CP 8888, Succ. A,

Montréal, QC H3C 3P8, Canada

e-mail: mateescu.m-alexandru@uqam.ca

R. Federico

Department of Biology, 3rd University of Rome,

00146 Rome, Italy

B. Mondovi

Department of Biochemical Sciences "Rossi-Fanelli",

University of Rome "La Sapienza",

00185 Rome, Italy almost constant in the simulated intestinal fluid (containing pancreatin or not), with a slight diminution in the presence of pancreatic proteases. After $10 \mathrm{~h}$ of incubation at $37{ }^{\circ} \mathrm{C}$, the DAO enzymatic activity from the vegetal extract was $44.7 \%$ in media without pancreatin and $13.6 \%$ in the presence of pancreatin, whereas the purified DAO retained only $4.65 \%$ of its initial enzymatic activity in the presence of pancreatin.

Keywords Diamine oxidase - Zymographic assay . Entrapped peroxidase polyacrylamide gel $\cdot$ Proteolytic stability $\cdot$ Simulated gastro-intestinal conditions

\section{Introduction}

Plant diamine oxidases (DAOs), also referred as histaminases [1], are homodimeric copper amine oxidases (EC 1.4.3.6), each subunit containing a single copper ion and 2,4,5-trihydroxyphenylalanine quinone/TPQ, a cofactor derived from the post-translational oxidation of a tyrosine residue [2]. They present a high specificity for primary diamines, able to oxidate biogenic amines to corresponding aldehyde, ammonia $\left(\mathrm{NH}_{3}\right)$, and hydrogen peroxide $\left(\mathrm{H}_{2} \mathrm{O}_{2}\right)$. Current DAO assays in solution measure the amine oxidase activity by spectrophotometrical methods, monitoring directly the absorbance of formed aldehydes [3] or by subsequent condensation of different compounds [4]. Other methods are based on radiometric assays, with $\left[1,4-{ }^{14} \mathrm{C}\right]$ putrescine as substrate [5], on oxymetric or polarographic methods measuring the rate of oxygen consumption in the presence of substrate [6] or on fluorimetric determinations [7], where homovanillic acid is converted into a highly fluorescent compound by the released $\mathrm{H}_{2} \mathrm{O}_{2}$ in the presence of peroxidase. All these methods are not giving information 
on the loss of molecular integrity of DAO (i.e., to acidic or proteolytic hydrolysis). Thus, supplemental information can be obtained using polyacrylamide gel electrophoresis (PAGE) by monitoring the protein pattern (staining gels with Coomassie Blue) and the enzymatic activity (zymography).

There are several major advantages of polyacrylamide (PAA) gels, such as: the high homogeneity of the gels with the density which can be easily modified to allow the best enzymes separation. The gels can be stained with Coomassie Brilliant Blue for protein profile and, keeping the same running conditions, a zymographic pattern can be directly visualized in some specific conditions and the enzyme activity can be quantified by densitometry. The zymographic PAGE is easy to run and the results are highly reproducible. As the $\mathrm{H}_{2} \mathrm{O}_{2}$ is the product of almost all oxidases, the gel areas occupied by DAO after its electrophoretic separation can be visualized via a coupled peroxidase reaction. Peroxidase as second enzyme is widely used to detect oxidase-producing $\mathrm{H}_{2} \mathrm{O}_{2}$ in presence of oxidizable dyes as its second substrate. Frequently used as donor substrate of peroxidase are: tetramethyl benzidine [8], 3,3'-diaminobenzidine [9], ortho-dianisidine [10], and guaiacol [11]. The chromogenic guaiacol method is one of the most commonly used on gels. However, this method has the disadvantage that the bands are stable only for a short period, requiring stabilization by Coomassie Brilliant Blue [11]. Similarly, the 3,3'-diaminobenzidine may also be used as a peroxidase chromogenic substrate, but developed bands have to be intensified by other treatments [9].

Some previous reports concern amineoxidases staining on PAA gels. Thus, Houen and Leonardsen [12] developed a specific staining method for DAO activity in the presence of peroxidase. The diaminobenzidine inhibited DAO and gave rise to unspecific staining, the most suitable among the substrates used being 4-Cl-1-naphtol. Lee et al. [13] used a peroxidase-coupled reaction in the presence of 3amino-9-ethylcarbazole to detect plasma amineoxidase activities after native polyacrylamide gel electrophoresis. In the mentioned studies, after the electrophoresis, the gels were kept in the presence of peroxidase solution to detect amineoxidase enzymatic activities. This present study proposes a method to detect the DAO enzymatic activity from Lathyrus sativus seedlings using sodium dodecyl sulfate polyacrylamide gel electrophoresis (SDS-PAGE) with the peroxidase immobilized in the PAA gel. This method allowed the study of DAO stability to proteolysis in simulated gastro-intestinal conditions. To our knowledge, this is the first zymographic assay reported for vegetal histaminase in the presence of SDS using the second enzyme (peroxydase) immobilized in the PAA gel. In the presented method, we proposed the ortho-phenylenediamine (OPDA) as donor substrate of peroxidase, with the formation of a stable product, azo-aniline, easily monitored on gels. The redox dyes, once oxidized, change in color and some of them also in solubility (from soluble when reduced to insoluble when oxidized). In our case, in the presence of $\mathrm{H}_{2} \mathrm{O}_{2}$ and peroxidase, OPDA changed from colorless to a yellow-brown compound stable and easy to detect on the gel. The two coupled enzymatic reactions to monitor the enzymatic activity of DAO on the SDS polyacrylamide gel containing entrapped peroxidase are:

Putrescine $+2 \mathrm{O}_{2}+2 \mathrm{H}_{2} \mathrm{O} \stackrel{\text { DAO }}{\longrightarrow}$ Aldehyde $+2 \mathrm{NH}_{3}+2 \mathrm{H}_{2} \mathrm{O}_{2}$

$2 \mathrm{H}_{2} \mathrm{O}_{2}+2 \mathrm{OPDA} \stackrel{\text { Peroxidase }}{\longrightarrow}$ Azo - aniline $+4 \mathrm{H}_{2} \mathrm{O}$

In our approach, the peroxidase is entrapped into the SDS polyacrylamide gels during polymerization and the DAO samples are deposited onto the gels for electrophoresis. After the electrophoretic run, gels are placed in solutions of putrescine (DAO substrate) and OPDA (peroxidase substrate). Both substrates diffuse into the gel and yellow-brown bands are developed in situ, corresponding to enzymatic activity of DAO.

A histaminase (DAO) of vegetal origin, more efficient than that of animal origin, was proposed for the general treatment of histamine-related pathologic conditions, such as allergic and septic shock, allergic asthma, anaphylaxis, allergic rhinitis and conjunctivitis, urticaria and atopic dermatitis, in which the histamine is the principal chemical mediator [14]. Plant histaminase can be obtained from different vegetal sources and can be used as a crude extract or as a purified enzyme. As previously shown with other copper oxidases (such as ceruloplasmin and serum bovine amine oxidase), which presented antioxidant, cardiomodulatory, and cardioprotective effects [15], vegetal DAO have beneficial effects in cardiac anaphylactic response [16] and in myocardial ischemia and reperfusion injury [17]. Plant histaminase has also some beneficial effects in asthma-like reaction [18], or in splanchnic artery occlusion/reperfusion injury [19]. As histamine and reactive oxygen species are involved in the pathophysiology of inflammatory bowel disease, hog kidney DAO had been intraperitoneally administered on experimental ulcerative colitis in rats [20], and the DAO treatment positively modified the inflammatory reaction. Thus, it is also expected that exogenous DAO could protect against oxidative damage [17-19], as reactive species also play an important role in inflammatory diseases. In this context, the vegetal DAO stability to proteolysis in the presence of digestive enzymes has to be known. A proteolysis study on a vegetal DAO purified from pea (Pisum sativum) seedlings was previously reported [21] in the presence of $0.01 \%$ pepsin (pH 2) and of 
$0.1 \%$ trypsin $(\mathrm{pH} 7.2)$. To our knowledge, there are no studies on vegetal histaminase in more acidic conditions ( $\mathrm{pH}$ 1.2) and over longer periods in simulated intestinal fluid, in the presence of pancreatin (containing trypsin and other proteases, together with other various digestive enzymes such as amylase, lipase, ribonuclease) [22]. In this context, the aim of this work was also to study in vitro the behavior of DAO from L. sativus seedlings extract to proteolytic action of digestive enzymes, in simulated gastric and intestinal conditions, using the zymographic assay described above.

\section{Experimental}

Materials

1,4-Diaminobutane dihydrochloride (putrescine), orthophenylenediamine dihydrochloride, peroxidase type I (from horseradish, 96 purpurogallin units/mg solid), Bradford Reagent, pepsin (from porcine gastric mucosa, 882 units/ $\mathrm{mg}$ protein), and pancreatin (from porcine pancreas) were purchased from Sigma-Aldrich Chemical Company (St. Louis, MO, USA). Acrylamide, $N, N^{\prime}$-methylene-bisacrylamide and protein molecular weight standards (Broad Range) were from Bio-Rad Laboratory (Richmond, VA, USA).

Preparation of vegetal extract from L. sativus seedlings and purification of DAO

The vegetal extract and the purified DAO from grass pea L. sativus seedlings were prepared as previously described [23], with minor modifications. Briefly, $500 \mathrm{~g}$ of freshly collected shoots of etiolated L. sativus seedlings were homogenized in a Waring blender with $1 \mathrm{~L}$ of $30 \mathrm{mM}$ $\mathrm{NaH}_{2} \mathrm{PO}_{4}$ (final $\mathrm{pH}$ 4.4), and then filtered. In these conditions, the DAO remains ionically linked to the insoluble fraction. The solid residue, mainly constituted by cell walls and vascular fibers, was washed with the same buffer and the enzyme was finally eluted from the solid residue with $500 \mathrm{~mL}$ of $0.1 \mathrm{M}$ sodium phosphate buffer (pH 7) and, then, centrifuged. The supernatant containing the DAO was lyophilized. The purification of DAO was done as previously described [23], onto a DE52-cellulose and a HiTrap SP Sepharose column.

Determination of protein concentration and of enzymatic activity of DAO preparations from $L$. sativus seedlings

Different concentrations of vegetal extract $(1,5,10,15,25$, $40 \mathrm{mg} / \mathrm{mL})$ or of purified DAO $(3 \mathrm{mg} / \mathrm{mL})$ were kept for $2 \mathrm{~h}$ at $4{ }^{\circ} \mathrm{C}$ in phosphate buffer solution (PBS, pH 7.4) under agitation and then, filtered and rapidly frozen. Protein concentrations of the vegetal extract and of the purified DAO were determined by the method of Bradford [24], using bovine serum albumin as standard. The enzymatic activity of DAO was assayed spectrophotometrically with the same two coupled reactions as for zymography assay, in the presence of putrescine $(30 \mathrm{mM})$ as substrate for DAO and of peroxidase as a second enzyme reaction, where OPDA is enzymatically oxidized into a colored compound (azo-aniline) by the released $\mathrm{H}_{2} \mathrm{O}_{2}$. The incubation mixture contained $640 \mu \mathrm{L}$ of PBS $(10 \mathrm{mM}$ sodium phosphate buffer, $\mathrm{pH} 7.4), 10 \mu \mathrm{L}$ of peroxidase solution $(0.1 \mathrm{mg} / \mathrm{mL})$, $50 \mu \mathrm{L}$ of OPDA solution $(30 \mathrm{mM}), 200 \mu \mathrm{L}$ of putrescine solution $(30 \mathrm{mM})$ and $100 \mu \mathrm{L}$ of DAO samples of unknown concentrations. The mixtures containing PBS, peroxidase, OPDA, and putrescine were incubated for $5 \mathrm{~min}$ at $37^{\circ} \mathrm{C}$, and then, the DAO samples were added. The enzymatic reactions were incubated at $37^{\circ} \mathrm{C}$ for $10 \mathrm{~min}$, when $100 \mu \mathrm{L}$ of $\mathrm{HCl}(4 \mathrm{M})$ were added and the final absorbance was read at $484 \mathrm{~nm}$ using a Beckman DU ${ }^{\circledR}-6$ spectrophotometer. The standard curve was prepared with serial concentrations of $\mathrm{H}_{2} \mathrm{O}_{2}$ from 0 to $68 \mu \mathrm{M}$.

One enzymatic unit (EU) of DAO is defined as the amount of enzyme catalyzing the oxidation of $1.0 \mu$ mole of putrescine per $10 \mathrm{~min}$ at $\mathrm{pH} 7.4$, at $37^{\circ} \mathrm{C}$.

\section{Proteolysis of DAO}

DAO was incubated in simulated gastro-intestinal conditions, with and without pepsin in simulated gastric fluid (SGF) or with and without pancreatin in simulated intestinal fluid (SIF) [22]. Samples of $40 \mathrm{mg}$ of vegetal extract powder were each incubated for $0,5,10,15,30,60$ and $120 \mathrm{~min}$ in $875 \mu \mathrm{L} \mathrm{SGF} \mathrm{(pH} \mathrm{1.2),} \mathrm{containing} \mathrm{or} \mathrm{not}$ pepsin $(0.32 \%$ powder with 882 units $/ \mathrm{mg}$ protein). In parallel, the same amounts of vegetal extract $(40 \mathrm{mg})$ were each incubated for $0,1,2,4,6,8$, and $10 \mathrm{~h}$ in $1 \mathrm{~mL}$ SIF (pH 6.8), containing or not pancreatin. The SIF containing pancreatin only was also incubated (as control) for the same periods of time as above. The incubations were done at $37^{\circ} \mathrm{C}$ and $50 \mathrm{rpm}$ using an incubator shaker (series 25D, New Brunswick Scientific Co., New Jersey, USA).

After each indicated SGF period, every SGF sample was neutralized with $125 \mu \mathrm{L}$ of $6.66 \%$ sodium bicarbonate solution and maintained under agitation for $2 \mathrm{~h}$ at $4{ }^{\circ} \mathrm{C}$. Then, the neutralized SGF samples (final concentration, $40 \mathrm{mg} / \mathrm{mL}$ ) were filtered and frozen. The SIF samples were only filtered and rapidly frozen. Purified DAO $(3 \mathrm{mg} / \mathrm{mL})$ was incubated only for $10 \mathrm{~h}$ in SIF containing pancreatin (pH 6.8, $37{ }^{\circ} \mathrm{C}$ and $50 \mathrm{rpm}$ ), then filtered and rapidly frozen.

The DAO standards were represented by the vegetal extract $(40 \mathrm{mg} / \mathrm{mL})$ or by the purified DAO $(3 \mathrm{mg} / \mathrm{mL})$ in 
PBS solution ( $\mathrm{pH}$ 7.4). Both standards were kept for $2 \mathrm{~h}$ under agitation at $4{ }^{\circ} \mathrm{C}$ and then filtered and frozen.

All the samples of histaminase were run in SDS-PAGE under non-reducing conditions.

Peroxidase entrapment in polyacrylamide gels

For the enzymatic detection of DAO on gels via the peroxidase-coupled reaction, the peroxidase was entrapped in the PAA gels. Thus, during the $8 \%$ PAA resolving gels preparation, $1 \mathrm{~mL}$ of horseradish peroxidase $(1 \mathrm{mg} / \mathrm{mL})$ was added to the gel solutions prior to polymerization (final volume of $5 \mathrm{~mL}$ ). Stacking gels contained no peroxidase. To verify the homogenous distribution of peroxidase in the polymerized gel, an $8 \%$ PAA resolving gel containing peroxidase (19.2 purpurogallin units) was electrophoretically tested for $1 \mathrm{~h}$ (room temperature, $120 \mathrm{~V}$ ) with no samples loaded on it. Then, the gel was immersed in a staining solution containing equal volumes of $\mathrm{H}_{2} \mathrm{O}_{2}$ $(30 \mathrm{mM})$ and OPDA $(30 \mathrm{mM})$ and kept under weak agitation for $1 \mathrm{~h}$. Another 8\% PAA resolving gel, containing no entrapped peroxidase and no samples loaded on it was treated in the same conditions (control).

Sodium dodecyl sulfate-polyacrylamide gel electrophoresis

The DAO protein content and the enzymatic activity of the vegetal samples incubated in PBS or in simulated gastric and intestinal conditions were evaluated by SDS-PAGE, using the electrophoresis system Mini-Protean II (Bio-Rad). Each sample was run in two PAA gels: one with entrapped peroxidase for zymography and another peroxidase-free for protein pattern.

Thus, the samples of vegetal extract at different concentrations in PBS $(1,5,10,15,25,40 \mathrm{mg} / \mathrm{mL})$, the neutralized SGF samples $(40 \mathrm{mg}$ vegetal extract $/ \mathrm{mL}$ in SGF, with or without pepsin), the SIF samples (40 mg vegetal extract $/ \mathrm{mL}$ in SIF, with or without pancreatin) and the samples of purified DAO $(3 \mathrm{mg} / \mathrm{mL}$ in SIF with pancreatin), prepared as described above, were defrosted and treated $(1: 1, v / v)$ with SDS electrophoresis sample buffer containing $0.12 \mathrm{M}$ Tris- $\mathrm{HCl}(\mathrm{pH}$ 6.8), 4\% SDS $(138 \mathrm{mM}), 20 \%$ glycerol, $0.004 \%$ bromophenol blue and no beta-mercaptoethanol. The mixtures were not heated. Then, $30 \mu \mathrm{L}$ of each treated sample were loaded and resolved by SDS-PAGE for $1 \mathrm{~h}$ and $15 \mathrm{~min}$ (room temperature, $120 \mathrm{~V}$ ) on $8 \%$ PAA peroxidase-free gels for Coomassie Blue staining of proteins or on $8 \%$ PAA gels containing entrapped peroxidase (19.2 purpurogallin units) for zymographic revelation of DAO enzymatic activity. The electrophoresis buffer used in electrophoresis runs contained $0.025 \mathrm{M}$ Tris-Base, $0.192 \mathrm{M}$ glycine, and $0.1 \%$ SDS.
The molecular weight protein standards were diluted in SDS reducing sample buffer (with beta-mercaptoethanol), heated for $5 \mathrm{~min}$ at $95^{\circ} \mathrm{C}$, then cooled and loaded $10 \mu \mathrm{L} /$ well to the PAA gel, as indicated in specifications from Bio-Rad.

\section{Coomassie Blue protein staining}

After electrophoresis, the 8\% PAA gels were incubated for $30 \mathrm{~min}$ (mild agitation) in a fixation solution containing methanol:acetic acid:water $(50 / 10 / 40, v / v / v)$ followed by $1 \mathrm{~h}$ of staining with $0.5 \%$ Coomassie Brilliant Blue G-250 in a methanol:acetic acid:water $(40 / 10 / 50, v / v / v)$ solution.

Detection of DAO enzymatic activity on polyacrylamide gels

After electrophoresis, the PAA gels containing entrapped peroxidase and electrophoretically separated DAO samples, were rinsed with distilled water and placed in a solution of putrescine $(30 \mathrm{mM})$ for a few minutes. Then, the incubation medium was completed with an equal volume of OPDA solution $(17 \mathrm{mM})$. The DAO enzymatic activity was detected on PAA gels (zymographic bands) in function of newly produced substrate $\left(\mathrm{H}_{2} \mathrm{O}_{2}\right)$ and in saturating concentration of chromogenic substrate (OPDA). Each substrate solution was prepared in PBS ( $\mathrm{pH}$ 7.4) and kept at $4{ }^{\circ} \mathrm{C}$ before utilization. The gels immersed in the two mentioned solutions were incubated at $37{ }^{\circ} \mathrm{C}(1 \mathrm{~h})$ under dark conditions and weak agitation. The position of DAO enzymatic activity bands on gels (zymograms) was determined by comparison of the electrophoretic patterns obtained from Coomassie staining, using DAO in PBS solution ( $\mathrm{pH}$ 7.4) as standard. The densitometry image analysis of gel bands was carried out using the Quantity One program (Bio-Rad). The DAO enzymatic activity measured by densitometry of bands was correlated with the DAO initial enzymatic activity (DAO in PBS, $\mathrm{pH}$ 7.4), spectrophotometrically determined. The DAO percentages were reported to standard, considering the standard (DAO in PBS, pH 7.4) as $100 \%$.

Influence of SDS on the enzymatic activity of DAO

The estimation of the DAO enzymatic activities monitored on the zymographic gels (EU/electrophoretic load of $30 \mu \mathrm{L}$, in the presence and the absence of SDS) and the dependence of DAO specific enzymatic activity on the time of incubation with SDS was studied spectrophotometrically at $25{ }^{\circ} \mathrm{C}$, in the same conditions as for electrophoresis. Thus, samples of vegetal extract in PBS $(1,5,10,15$, $25,40 \mathrm{mg} / \mathrm{mL})$ were treated $(1: 1, v / v)$ with an electrophoresis buffer containing $0.12 \mathrm{M}$ Tris $-\mathrm{HCl}(\mathrm{pH} 6.8), 20 \%$ 
glycerol, in the presence or the absence of $4 \%$ SDS $(138 \mathrm{mM})$, for the determination of the DAO enzymatic activities as EU/electrophoretic load of $30 \mu \mathrm{L}$. The dependence of DAO specific enzymatic activity on the time of incubation was studied after $0,30,75$, and $135 \mathrm{~min}$ at $25{ }^{\circ} \mathrm{C}$, on a sample of $40 \mathrm{mg}$ vegetal extract $/ \mathrm{mL}$, in the same electrophoresis buffer and in the presence or in the absence of SDS. The DAO enzymatic activities were determined by the same spectrophotometrical method described above, using the two coupled reactions in solution.

\section{Results and discussion}

The protein content of $L$. sativus vegetal extract, determined by Bradford assay [24], was in a linear dependency
$\left(R^{2}=0.9978\right)$ with the vegetal extract concentrations $(1,5$, $10,15,25,40 \mathrm{mg} / \mathrm{mL})$, indicating a good homogeneity of the extract powder (data not shown). The same concentrations of vegetal extract as mentioned above (with a total protein content of $15 \pm 1.4 \mu \mathrm{g} / \mathrm{mL}, 132 \pm 8 \mu \mathrm{g} / \mathrm{mL}, 302 \pm$ $13 \mu \mathrm{g} / \mathrm{mL}, 435 \pm 17 \mu \mathrm{g} / \mathrm{mL}, 719 \pm 33 \mu \mathrm{g} / \mathrm{mL}$ and, respectively, $1,091 \pm 27 \mu \mathrm{g} / \mathrm{mL}$ ) were then used on electrophoretic gels to follow the DAO protein content (Coomassie coloration) and the DAO enzymatic activity (zymography). The same migration patterns of molecular weight standards and of vegetal extract were obtained for either gels containing or not entrapped peroxidase after Coomassie coloration (data not shown). Thus, throughout the whole study, we used gels containing entrapped peroxidase only for the enzymatic activity evaluation of DAO (zymography).

To our knowledge, this is the first zymographic assay for plant histaminase with the second enzyme (peroxidase)
Fig. 1 Electrophoretic pattern of vegetal extract from

L. sativus seedlings. Coomassie staining: a SDS-PAGE $(8 \%$ PAA resolving gel without peroxidase) of different concentrations of DAO vegetal extract $(1,5,10,15,25,40 \mathrm{mg}$ powder/ $\mathrm{mL})$, treated $(1: 1, v / v)$ with nonreducing SDS loading buffer (30 $\mu \mathrm{L} /$ well). The gels were stained with Coomassie Brilliant Blue G-250. b Image analysis of DAO bands intensity with the Quantity One program. $n=3$. Zymographic DAO enzymatic activities: c different concentrations of DAO vegetal extract $(1,5,10,15,25,40 \mathrm{mg}$ powder/ $\mathrm{mL})$, treated $(1: 1, v / v)$ with nonreducing SDS loading buffer (30 $\mu \mathrm{L} /$ well). Oxidase activity was directly monitored on $8 \%$ PAA gels (containing entrapped peroxidase) after the electrophoretic run, in the presence of putrescine and orthophenylenediamine. d Image analysis of DAO bands intensity (enzymatic activity) with the Quantity One program. e Enzymatic activities of DAO on gel (EU/electrophoretic load of $30 \mu \mathrm{L})$, spectrophotometrically determined, in function of the vegetal extract concentrations. Protein content of vegetal extract: $15 \pm 1.4 \mu \mathrm{g} / \mathrm{mL}(1 \mathrm{mg} / \mathrm{mL})$, $132 \pm 8 \mu \mathrm{g} / \mathrm{mL}(5 \mathrm{mg} / \mathrm{mL}), 302 \pm$ $13 \mu \mathrm{g} / \mathrm{mL}(10 \mathrm{mg} / \mathrm{mL})$, $435 \pm 17 \mu \mathrm{g} / \mathrm{mL}(15 \mathrm{mg} / \mathrm{mL}), 719 \pm$ $33 \mu \mathrm{g} / \mathrm{mL}(25 \mathrm{mg} / \mathrm{mL}), 1,091 \pm$ $27 \mu \mathrm{g} / \mathrm{mL}(40 \mathrm{mg} / \mathrm{mL}) . n=3$ a)

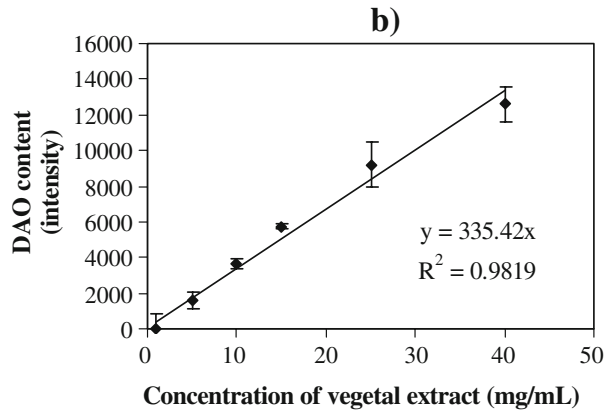

e)

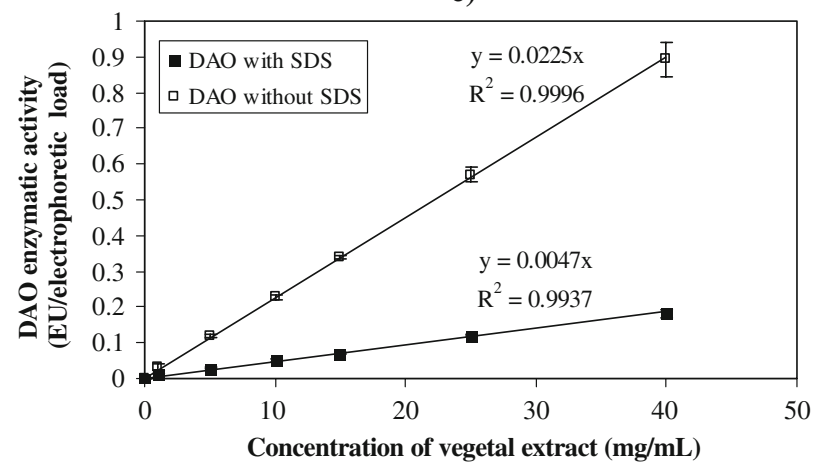

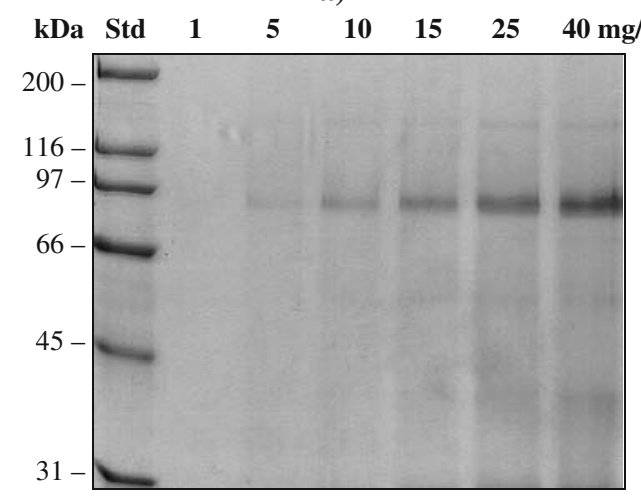

b)

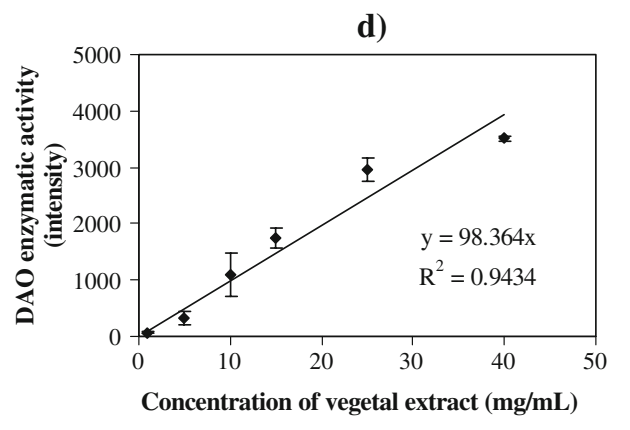

c)

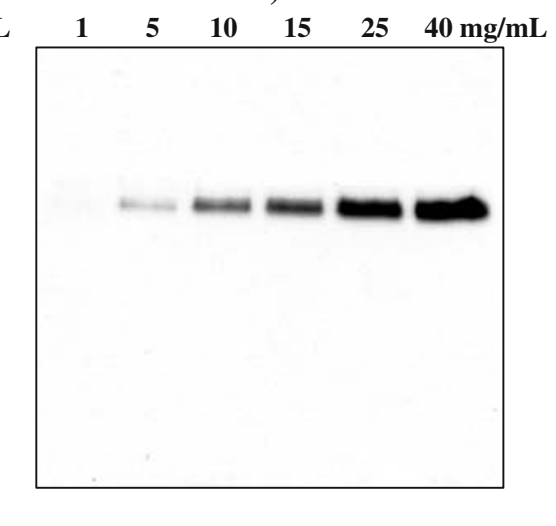

d)

$$
\text { (1) }
$$


entrapped in the PAA gel. As control, after an electrophoresis run without any DAO-loaded samples, the PAA resolving gel, containing entrapped peroxidase, was colored in a few minutes and in a homogenous manner in the presence of $\mathrm{H}_{2} \mathrm{O}_{2}$ and OPDA solutions. This indicated that the entrapped peroxidase still kept its enzymatic activity and that it was uniformly distributed in the PAA resolving gel. The gel without entrapped peroxidase, kept under the same conditions as above, remained totally transparent even after $1 \mathrm{~h}$ of incubation (data not shown). There are lots of applications with peroxidase physically entrapped in gels. In our case, the enzyme was immobilized during polymerization of PAA gels (a covalent immobilization during the polymerization process of acrylamide gels involving double bonds of the prosthetic group of peroxidase is not excluded). Thus, despite the molecular weight of peroxidase $(40 \mathrm{kDa})$, much lower than that of DAO from $L$. sativus (approximately $150 \mathrm{kDa}$ ), peroxidase did not migrate during the electrophoresis run, suggesting its immobilization into the PAA gel during the polymerization process, a fact also reported by Ugarova et al. [25], who studied the catalytic properties and stability of immobilized horseradish peroxidase into a PAA gel.

It is known that in denaturing SDS-PAGE, migration of proteins is determined primarily on their molecular mass. A single band in reducing SDS-PAGE corresponding to a molecular mass of $72 \mathrm{kDa}$ [23] was reported for DAO from L. sativus. In non-reducing SDS-PAGE (without betamercaptoethanol and without heating of samples, which both can disrupt the folded structure of enzyme), the electrophoretic mobility of proteins depends more on their hydrodynamic size. Thus, the SDS-PAGE pattern of the analyzed vegetal extract presented a major protein band, identified as DAO, whose growing intensity was in function of the concentration of the loaded vegetal extract (Fig. 1a). Gel images were densitometrically analyzed using the Quantity One program and a linear variation of histaminase content (protein band intensity) with the concentrations of vegetal extract was obtained (Fig. 1b). The combination of SDS-PAGE protein pattern (Coomassie staining) and of zymogram technique allowed to determine comparatively the position of zymographic bands corresponding to DAO enzymatic activity (Fig. 1c). The $\mathrm{H}_{2} \mathrm{O}_{2}$, the product of enzyme reaction of DAO and substrate for peroxidase, will generate, in the presence of OPDA dye (second substrate for peroxidase), a colored oxidized product (azo-aniline) with intensity related to the amount of released $\mathrm{H}_{2} \mathrm{O}_{2}$ resulted from DAO enzyme activity. The oxidized product of the two coupled enzymatic reactions is thus constantly accumulated on the gel. In all cases, the zymograms revealed only a single yellowbrown band on a colorless background, attributed to the DAO activity of histaminase, with intensity of bands growing in function of the concentration of vegetal extract, showing a linear dependency (Fig. 1d). Normally, the SDS contributes to unfold an enzyme by interacting with the non-polar amino acid side-chains situated in the interior of the folded protein structure. In our non-reducing conditions (without beta-mercaptoethanol and without heating of samples), the DAO still retained its enzymatic activity in the presence of SDS, a linear dependency being obtained between DAO enzymatic activity (EU/electrophoretic load) and the concentrations of the vegetal extract, either in the presence or the absence of SDS (Fig. 1e).

The SDS is known to interact with most of water soluble proteins to form protein-detergent complexes [26]. Many enzymes lose their activity in the presence of SDS and some are activated [27, 28]. Gebicka [29] showed that horseradish peroxidase in solution is relatively resistant against SDS, the enzyme retaining its full activity up to $20 \mathrm{~min}$ when incubated at room temperature with $100 \mathrm{mM}$ SDS, and still retained $63 \%$ of its activity after the next $4 \mathrm{~h}$. To our knowledge, there are no studies on vegetal histaminase in the presence of SDS. Since in our case, it was observed that DAO still retained part of its enzymatic activity on PAA gels in the presence of SDS (Fig. 1c-e), it was of interest to study the stability of vegetal DAO in solution in the presence of SDS, using the same conditions as for electrophoresis. Thus, in the absence of SDS, the enzymatic activity of DAO was kept constant during the first $30 \mathrm{~min}$ of incubation $\left(25^{\circ} \mathrm{C}\right)$, and then, its activity significantly diminished (Fig. 2). In the presence of $69 \mathrm{mM}$ SDS, the DAO specific activity was rapidly reduced, but then being stabilized for the entire period of $135 \mathrm{~min}$ of

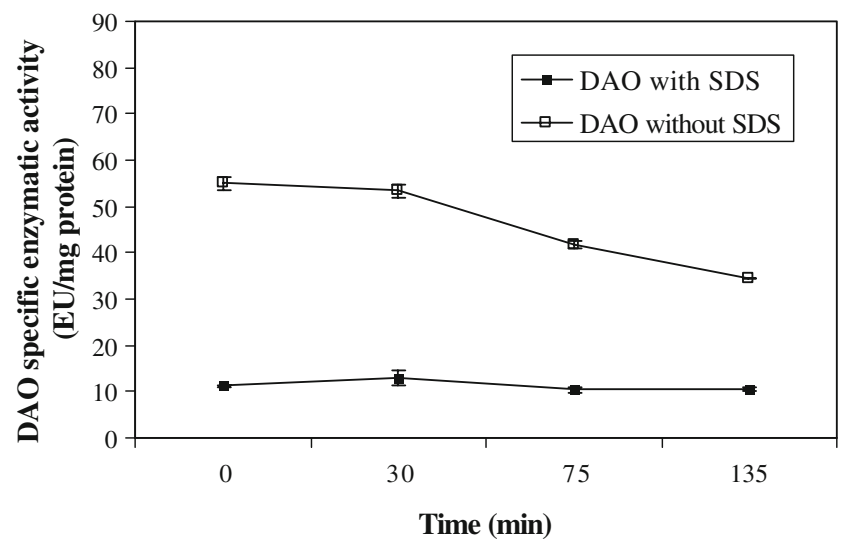

Fig. 2 The influence of sodium dodecyl sulfate on the enzymatic activity of DAO. The specific enzymatic activity of DAO (EU/mg protein) from vegetal extract $(40 \mathrm{mg} / \mathrm{mL}$, containing $1,091 \pm 27 \mu \mathrm{g}$ total protein $/ \mathrm{mL}$ ) was measured at $25{ }^{\circ} \mathrm{C}$ in a solution containing $60 \mathrm{mM}$ Tris $-\mathrm{HCl}(\mathrm{pH} \mathrm{6.8}), 10 \%$ glycerol, in the presence or the absence of $69 \mathrm{mM}$ SDS. The DAO specific enzymatic activities were determined spectrophotometrically, as described before, with putrescine as DAO substrate and ortho-phenylenediamine as co-substrate for peroxidase; $n=3$ 
incubation in SDS (Fig. 2). This stabilization of the enzymatic activity in the presence of SDS for more than $2 \mathrm{~h}$ is important, since the revelation of enzymatic activity of DAO on PAA gels was done after $75 \mathrm{~min}$ of electrophoresis and during $60 \mathrm{~min}$ of gel incubation. The decrease of DAO enzymatic activity by SDS was also settled as percentage from the original DAO specific activity (in the absence of SDS), which was considered as $100 \%$. Thus, $30 \%$ of DAO enzymatic activity was still detected after $135 \mathrm{~min}$ of incubation in the presence of SDS. The presence of SDS in the electrophoresis conditions (SDS-PAGE) contributed to a better resolution of DAO separation comparatively to native PAGE (data not shown), improving mobility and stabilizing the DAO.
The behavior of DAO from $L$. sativus seedlings extract (40 mg vegetal extract $/ \mathrm{mL}$ containing $1,091 \pm 27 \mu \mathrm{g}$ total protein $/ \mathrm{mL}$ ) under proteolytic action of digestive enzymes was studied in SGF (with or without pepsin) and in SIF (with or without pancreatin) [22]. Thus, DAO electrophoretic bands corresponding to its protein content and its enzymatic activity were revealed on electrophoretic gels for DAO in PBS (pH 7.4) and in neutralized SGF (with or without pepsin), at $0 \mathrm{~min}$ of SGF treatment (Fig. 3). In acidic conditions ( $\mathrm{pH}$ 1.2), the degradation and inactivation of DAO (with no detectable DAO enzymatic activity on gels) were observed after $15 \mathrm{~min}$ of incubation at $37^{\circ} \mathrm{C}$ and $50 \mathrm{rpm}$ (Fig. 3a, b). The pH of an enzyme medium can affect the state of ionization of amino acid side-chains that
Fig. 3 Electrophoretic pattern of diamine oxidase from the vegetal extract of $L$. sativus seedlings in simulated gastric fluid (SGF, pH 1.2). SGF without pepsin $(\mathbf{a}, \mathbf{b})$ and SGF with pepsin $(\mathbf{c}, \mathbf{d})$. Coomassie staining gels without peroxidase (a, c) and DAO zymographic gels containing entrapped peroxidase $(\mathbf{b}, \mathbf{d})$ of vegetal extract (40 mg/mL, containing 1,091 $27 \mu \mathrm{g}$ total protein $/ \mathrm{mL}$ ) from L. sativus seedlings in $\mathrm{PBS}, \mathrm{pH}$ 7.4 and in SGF (up to $120 \mathrm{~min}$ of incubation). The vegetal extract samples in SGF (with or without pepsin) were neutralized with sodium bicarbonate, and then treated with non-reducing SDS loading buffer $(1: 1, v / v)$ and loaded $30 \mu \mathrm{L} /$ well. DAO protein content (e) and DAO enzymatic activity (f) in SGF. Results are expressed in percentage, considering DAO in PBS as $100 \%$. Quantity One program was used for densitometric analysis of gel images. The DAO specific enzymatic activity of $11.21 \pm$ $0.31 \mathrm{EU} / \mathrm{mg}$ protein, determined spectrophotometrically in PBS solution (in the presence of SDS), was considered as $100 \% ; n=3$ a)

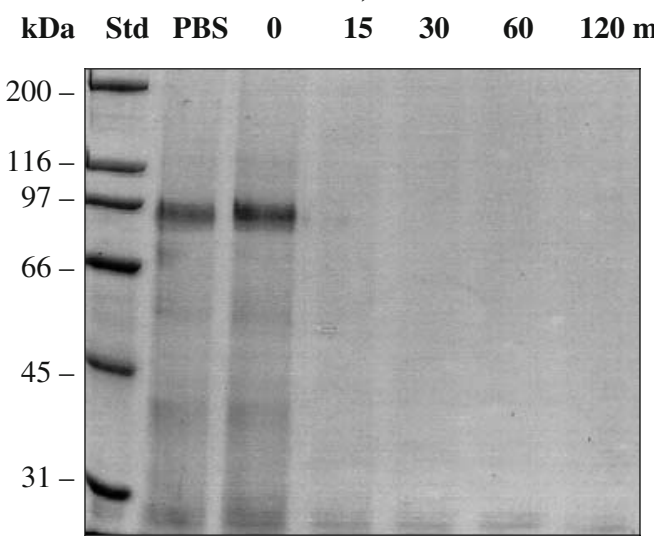

c)

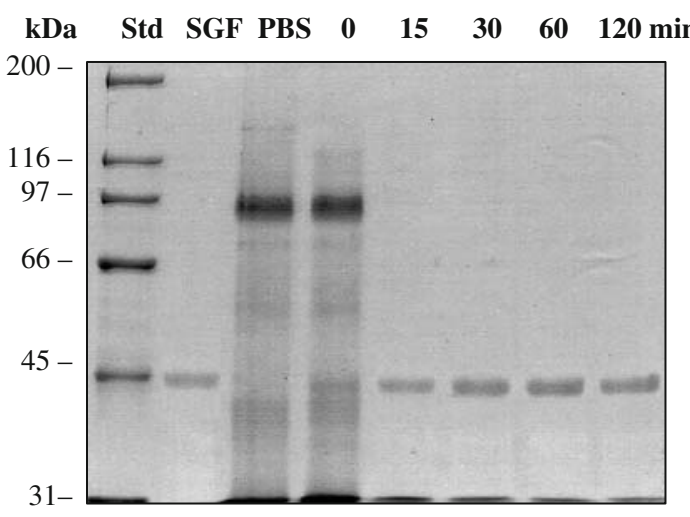

e)

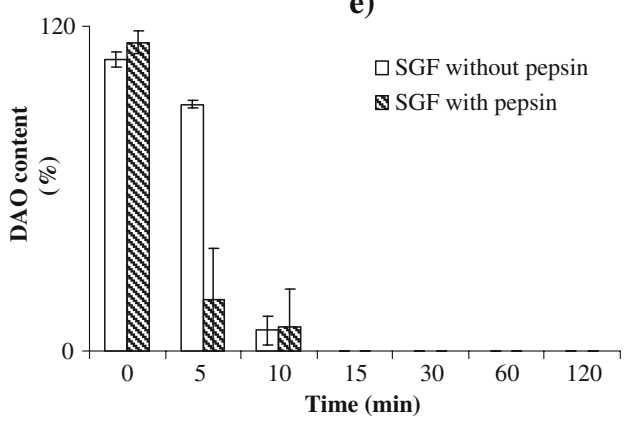

b)

$\begin{array}{llllll}\text { PBS } & 0 & 15 & 30 & 60 & 120\end{array}$



d)

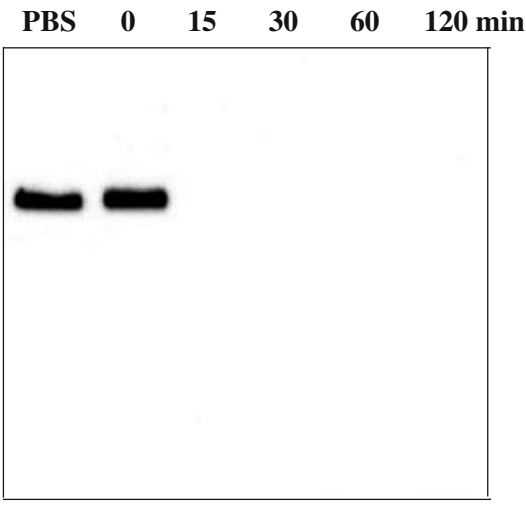

f)




may be involved in the maintenance of the folded structure. Furthermore, in strong acidic conditions ( $\mathrm{pH}$ 1.2), a possible hydrolysis can also occur with the degradation of the proteins contained in the vegetal extract (Fig. 3a). Federico et al. [21] reported that at $\mathrm{pH} 2$ and in the presence of pepsin $(0.01 \%, 4,500$ units $/ \mathrm{mg})$, purified histaminase from pea seedlings ( $P$. sativum) was partially inactivated after $30 \mathrm{~min}$ of incubation (14\% remaining enzymatic activity), with complete loss of activity after $60 \mathrm{~min}$ of incubation. In more acidic conditions $(\mathrm{pH} 1.2)$ and in the presence of pepsin $(0.32 \%$ with 882 units $/ \mathrm{mg}$ protein) [22], the total degradation of all the proteins present in the vegetal extract from $L$. sativus seedlings was observed after 15 min of incubation (Fig. 3c), with no detectable DAO enzymatic activity (Fig. 3d). The remaining band found for samples incubated at 15, 30, 60, and 120 min corresponds to pepsin which is stable in gastric acidity (Fig. 3c).

The time course in SGF, in the absence or in the presence of pepsin, indicated a fast degradation of DAO in early stage of incubation (Fig. 3e,f). Thus, after $5 \mathrm{~min}$ of acidic incubation, a loss of about $10 \%$ of DAO content and of $15 \%$ of DAO activity detected on gels was observed. At $10 \mathrm{~min}$, the degradation of DAO was more advanced, and, after $15 \mathrm{~min}$, its degradation was complete. In the presence of pepsin, the DAO degradation was even faster, with total loss of its enzymatic activity in less than $10 \mathrm{~min}$.

Previous proteolysis studies with other amine oxidases, such as swine kidney diamine oxidase (SKDAO) and bovine serum amine oxidase (BSAO), were done separately with trypsin, pronase, or with thermolysin for a period of up to $4 \mathrm{~h}$ [30]. The SKDAO in the presence of trypsin or pronase partially lost its enzymatic activity in the first $60 \mathrm{~min}$, followed by stabilization during the next $3 \mathrm{~h}$ of proteolysis. In the case of trypsin, the SKDAO activity was stabilized at about $50 \%$ after $4 \mathrm{~h}$ of hydrolysis. In the presence of thermolysin, the SKDAO lost more than $60 \%$ of its initial activity after $4 \mathrm{~h}$ of proteolysis. Concerning the $\mathrm{BSAO}$, the pronase exerted the highest denaturing effect, with only $40 \%$ remaining enzymatic activity after $4 \mathrm{~h}$ of hydrolysis. There are not many studies on vegetal histaminase stability to proteolysis in the presence of pancreatic enzymes. Federico et al. [21] tested purified vegetal histaminase from $P$. sativum seedlings only for $60 \mathrm{~min}$ in the presence of trypsin, when $67 \%$ of its enzymatic activity was retained. In our study, pancreatin, containing enzymes such as trypsin, chymotrypsin, endopeptidases, exopeptidases, carboxypeptidases, as well as other digestive enzymes (amylase, lipase, ribonuclease), was used to test the proteolysis stability of DAO from $L$. sativus over longer periods, up to $10 \mathrm{~h}$. During $10 \mathrm{~h}$ of vegetal extract incubation in pancreatin-free $\mathrm{SIF}(\mathrm{pH} 6.8)$ at $37{ }^{\circ} \mathrm{C}$ and $50 \mathrm{rpm}$, the DAO protein content was kept constant as indicated after Coomassie Blue staining (Fig. 4a), with a slight diminution of its enzymatic activity on the corresponding zymogram (Fig. 4b). Interestingly, in the presence of pancreatin, in the same conditions as before (SIF, pH 6.8), the DAO from the vegetal extract was still present after $10 \mathrm{~h}$ of incubation, as indicated by Coomassie
Fig. 4 Stability of diamine oxidase from L. sativus vegetal extract in simulated intestinal fluid (SIF, pH 6.8). SIF without pancreatin $(\mathbf{a}, \mathbf{b})$ and SIF with pancreatin $(\mathbf{c}, \mathbf{d})$. Coomassiestained gels without peroxidase $(\mathbf{a}, \mathbf{c})$ and DAO zymographic gels containing entrapped peroxidase $(\mathbf{b}, \mathbf{d})$ of vegetal extract $(40 \mathrm{mg} / \mathrm{mL}$, containing $1,091 \pm 27 \mu \mathrm{g}$ total protein $/ \mathrm{mL}$ ) from $L$. sativus seedlings in PBS, pH 7.4 and in SIF (up to $10 \mathrm{~h}$ of incubation). The vegetal extract samples in SIF (with or without pancreatin) were treated with non-reducing SDS loading buffer $(1: 1, v / v)$ and loaded $30 \mu \mathrm{L} /$ well; $n=3$

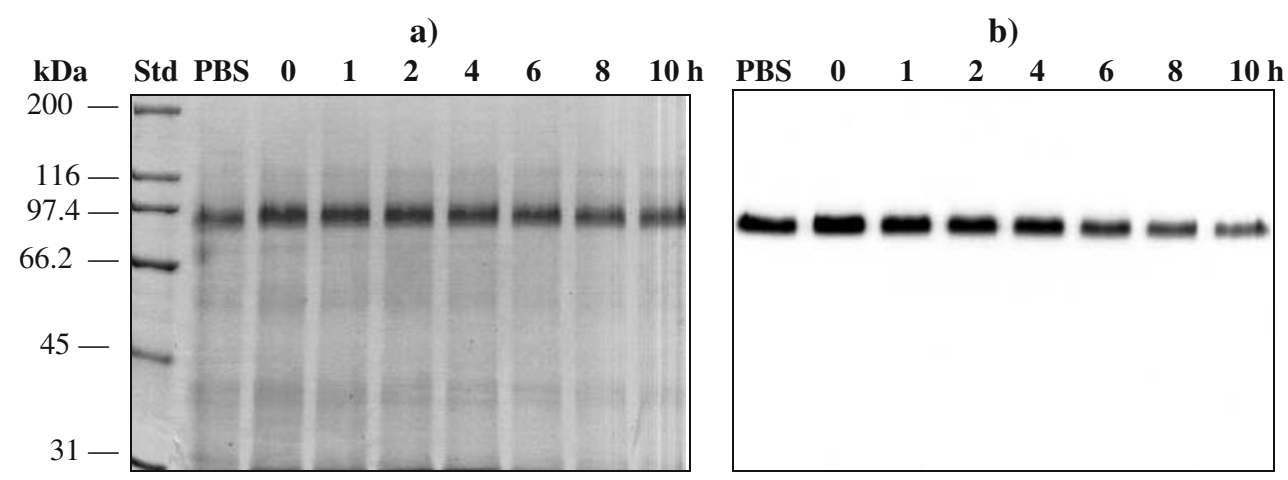

c)

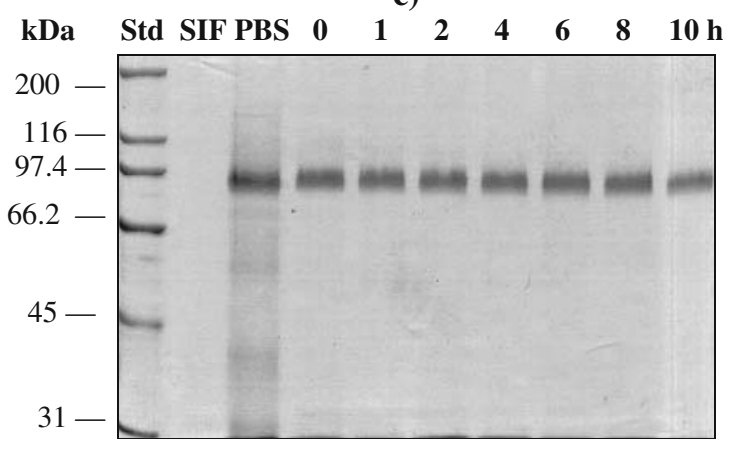

d)

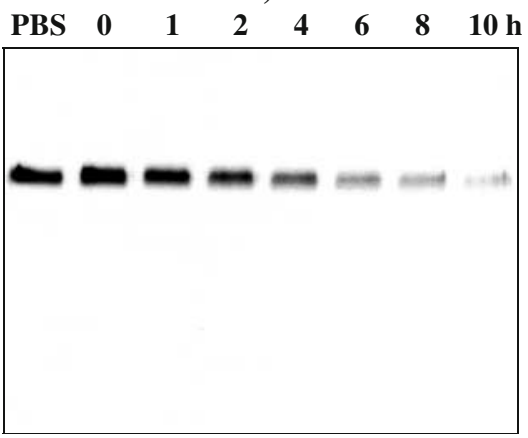


protein staining (Fig. 4c). The corresponding zymogram still showed a band ascribed to DAO enzymatic activity even after $10 \mathrm{~h}$ of incubation in the presence of pancreatin (Fig. 4d), indicating a certain stability of DAO to pancreatin proteolysis. As control, SIF containing pancreatin only was spectrophotometrically checked for amine oxidase, and no activity was found over the $10 \mathrm{~h}$ of incubation (data not shown). This confirms the lack of additional interfering amine oxidases due to eventual microbial contamination during the long incubation. The densitometric analysis (Fig. 5) confirmed that the DAO protein content was almost constant either in the absence or presence of pancreatin, with a slight decrease in the presence of pancreatin (Fig. 5a). After $10 \mathrm{~h}$ of incubation at $37{ }^{\circ} \mathrm{C}(50 \mathrm{rpm})$, the DAO activity from the vegetal extract was $44.7 \%$ in SIF

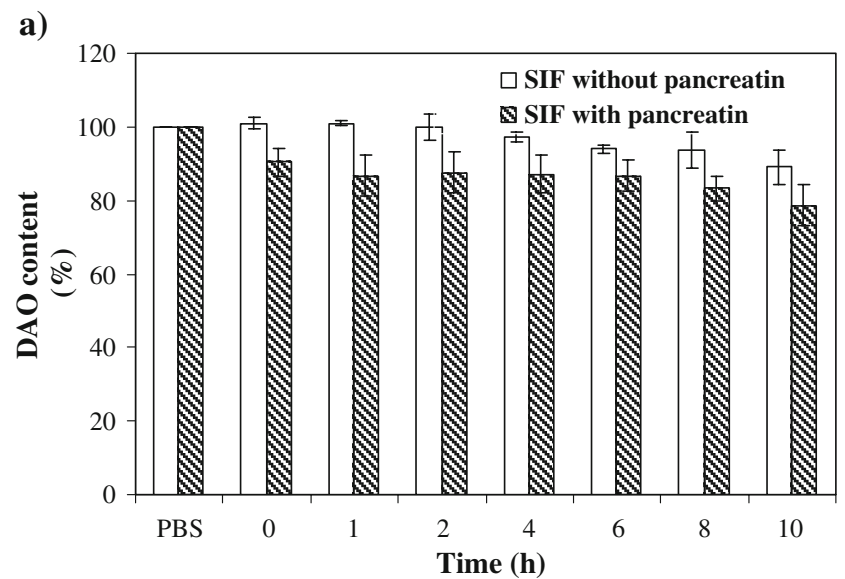

b)

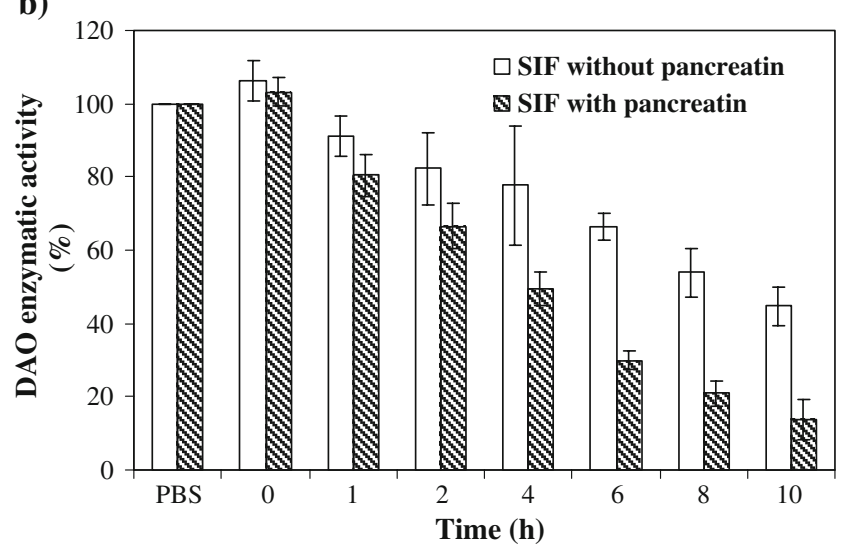

Fig. 5 Densitometric analysis of diamine oxidase from L. sativus vegetal extract after incubation in simulated intestinal fluid (SIF, $\mathrm{pH}$ 6.8 ), with or without pancreatin. a DAO protein content (\%), b DAO enzymatic activity (expressed in \% from the specific activity of DAO in PBS). Results are expressed in percentage, considering DAO in PBS as $100 \%$. Quantity One program was used for densitometric analysis of gel images. The vegetal extract $(40 \mathrm{mg} / \mathrm{mL})$ contained $1,091 \pm 27 \mu \mathrm{g}$ total protein $/ \mathrm{mL}$ in PBS/SIF. The DAO specific enzymatic activity of $11.21 \pm 0.31 \mathrm{EU} / \mathrm{mg}$ protein, determined spectrophotometrically in PBS (in the presence of SDS), was considered as $100 \% ; n=3$ without pancreatin and $13.6 \%$ in the presence of pancreatin (Fig. 5b).

To evaluate the influence of the presence of the other proteins from the L. sativus vegetal extract on DAO proteolysis, a purified DAO preparation (containing $413 \pm$ $9 \mu \mathrm{g}$ protein $/ \mathrm{mL}$ with a specific enzymatic activity of $110.43 \pm 2.01 \mathrm{EU} / \mathrm{mg}$ protein, determined in the presence of SDS) from the same vegetal source was also tested for $10 \mathrm{~h}$ $\left(37^{\circ} \mathrm{C}, 50 \mathrm{rpm}\right)$ only in the presence of pancreatin (SIF, $\mathrm{pH}$ 6.8). The densitometric analysis of purified DAO protein content and of its enzymatic activity was realized, considering the purified DAO in PBS (pH 7.4) as standard $(100 \%)$. After $10 \mathrm{~h}$ of incubation in the presence of pancreatin, the protein content of purified DAO diminished to $59.7 \%$ (data not shown), more than in the case of DAO from vegetal extract, which decreased to $78.7 \%$ after $10 \mathrm{~h}$ (Fig. 5a), suggesting a higher susceptibility at proteolysis of the purified histaminase samples. Concerning the DAO enzymatic activity, after $10 \mathrm{~h}$ of incubation in the same conditions as before, only $4.65 \%$ of purified DAO activity was still present (data not shown), compared to $13.6 \%$ obtained with the vegetal extract (Fig. 5b). These results suggest a possible protection of DAO afforded by the other proteins present in the vegetal extract or a possible presence of some protease inhibitors in the vegetal extract able to partially protect the DAO against pancreatin proteolysis. The elucidation of these aspects, explaining better stability to proteolysis in the case of the vegetal extract, will be the object of a further investigation.

\section{Conclusion}

A zymographic method was developed for the monitoring of DAO activity on immobilized peroxidase in polyacrylamide gels, with putrescine as substrate of DAO and OPDA as second substrate for peroxidase. Combination of protein pattern obtained in SDS-PAGE with that of enzymatic activity obtained in zymography can give valuable information on protein stability and enzymatic activity of DAO. Furthermore, a correlation between the DAO content and its enzymatic activity from a vegetal extract can be established in different conditions (i.e., proteolysis). The data obtained by this method indicated a certain stability at proteolysis of vegetal DAO, an aspect which can be of interest for eventual therapeutic application of this enzyme. This method can also be used on native PAGE gels, as an alternative method to evaluate the DAO enzymatic activity.

Acknowledgments The graduate studentship from Natural Sciences and Engineering Research Council of Canada (NSERC) granted to Carmen Calinescu and support from CRIP (FQRNT) are gratefully acknowledged. Thanks are due to Dr. Canh LeTien for useful discussions. 
Open Access This article is distributed under the terms of the Creative Commons Attribution Noncommercial License which permits any noncommercial use, distribution, and reproduction in any medium, provided the original author(s) and source are credited.

\section{References}

1. Mondovi B, Rotilio G, Finazzi A, Scioscia-Santoro A (1964) Biochem J 91:408-415

2. Klinman JP, Mu D (1994) Ann Rev Biochem 63:299-344

3. Tabor CW, Tabor H, Rosenthal SM (1954) J Biol Chem 208: 645-661

4. Holt A, Sharman DF, Baker GB, Palcic MM (1997) Anal Biochem 244:384-392

5. Kusche J, Richter H, Hesterberg R, Schmidt J, Lorenz W (1973) Agents Actions 3:148-156

6. Befani O, Sabatini S, Mateescu MA, Mondovi B (1989) Biochem Biophys Res Commun 163:1168-1174

7. Matsumoto T, Furuta T, Nimura Y, Suzuki O (1982) Biochem Pharmacol 31:2207-2209

8. Mesulam M-M (1978) J Histochem Cytochem 26:106-117

9. Iida R, Yasuda T, Nadano D, Kishi K (1990) Electrophoresis $11: 852$

10. Rudrappa T, Lakshmanan V, Kaunain R, Singara NM, Neelwarne B (2007) Food Chem 105:1312-1320

11. Fieldes MA (1992) Electrophoresis 13:454

12. Houen G, Leonardsen L (1992) Anal Biochem 204:296-299

13. Lee M-H, Chuang M-T, Hou W-C (2002) Electrophoresis 23:2369-2372

14. Mondovi B, Befani O, Federico R, Mateescu MA, Masini E, Mannaioni PF, Vannaci A (2002) Int Patent Publ No: WO 2002/043745
15. Mateescu MA, Nadeau R (2009) In: Floris G, Mondovi B (eds) Copper amine oxidases: structures, catalytic mechanisms, and role in pathophysiology. CRC

16. Masini E, Vannacci A, Marzocca C, Mannaioni PF, Befani O, Federico R, Toma A, Mondovi B (2002) Biochem Biophys Res Commun 296:840-846

17. Masini E, Pierpaoli S, Marzocca C, Mannaioni PF, Pietrangeli P, Mateescu MA, Zelli M, Federico R, Mondovi B (2003) Biochem Biophys Res Commun 309:432-439

18. Masini E, Vannacci A, Giannini L, Befani O, Nistri S, Mateescu MA, Mannaioni PF, Mondovi B, Federico R (2004) Eur J Pharmacol 502:253-264

19. Masini E, Cuzzocrea S, Bani D, Mazzon E, Muja C, Mastroianni R, Fabrizi F, Pietrangeli P, Marcocci L, Mondovi B, Mannaioni PF, Federico R (2007) Shock 27:409-415

20. Fogel WA, Lewinski A (2006) Inflamm Res 55:S63-S64

21. Federico R, Befani O, Mondovi B, Mulhbacher J, Mateescu MA (2000) Inflamm Res 49:S60-S61

22. U.S. Pharmacopeia National Formulary U.S.P. XXIV, NF XIX, United States Pharmacopeial Convention Inc., Rockville, MD, 2000

23. Federico R, Cona A, Caliceti P, Veronese FM (2006) J Control Rel 115:168-174

24. Bradford MM (1976) Anal Biochem 72:248-254

25. Ugarova NN, Kershengol'ts BM, Artamonov ID, Berezin IV (1976) Biokhimiia 41:1662-1670

26. Ibel K, May RP, Kirschner K, Szadkowski H, Mascher E, Lundahl P (1990) Eur J Biochem 190:311-318

27. Schrock HL, Gennis RB (1977) J Biol Chem 252:5990-5995

28. Moore BM, Flurkey WH (1990) J Biol Chem 265:4982-4988

29. Gebicka L (1999) Int J Biol Macromol 24:69-74

30. Mondovi B, Befani O, Mateescu MA (1992) Life Chem Reports $10: 151-155$ 